\title{
Titanium Modulates Immune System and Bone Metabolism
}

\author{
Ricardo Trindade ${ }^{1}$, Tomas Albrektsson ${ }^{1,2}$, Pentti Tengvall2, Ann Wennerberg ${ }^{3}$ \\ ${ }^{1}$ Department of Prosthodontics, Faculty of Odontology, Malmö University, Malmö , Sweden \\ 2Department of Biomaterials, Institute of Clinical Sciences, Gothenburg University, Gothenburg, Sweden \\ ${ }^{3}$ Department of Prosthodontics, Sahlgrenska Academy, Gothenburg University, Gothenburg, Sweden
}

\section{Introduction}

The concept of titanium implants being inert when in contact with the bone has been challenged ${ }^{1,2}$ and the hypothesis of an immune interaction between titanium and host bone tissue has been proposed ${ }^{2}$, following the concept of foreign body reaction to biomaterials ${ }^{3}$. The authors believe this concept is important to understand the processes leading to osseointegration and the development of peri-implantitis, which may depend of an intimate relationship between the immune system and bone cells.

A pilot study was designed with the aim to study the immune system during bone healing in the absence and presence of a titanium implant ${ }^{4}$.

\section{Material and Methods}

Six New Zealand white rabbits had an osteotomy performed on the distal portion of the femur on both sides: on one side a sham site was left to heal without an implant (Sh) and on the other side a titanium implant was placed (Ti). Three rabbits were sacrificed at 10 days and three rabbits at 28 days (within and after the inflammatory period of approximately 14 days $^{3}$, respectively). On each time point implants were removed and bone was collected from the periphery of both Sh and $\mathrm{Ti}$ sites and processed using quantitative-polymerase chain reaction (qPCR) for gene expression analysis. A panel of three reference genes was used and specific study markers were chosen (table 1).

\begin{tabular}{|l|l|}
\hline Biological Marker & Primer \\
\hline Neutrophil & NCF-I \\
\hline Macrophage & CD68, CDI Ib, CD I4, ARG I \\
\hline Macrophage fusion & IL-4, IL-I3, M-CSF \\
\hline Bone resorption & $\begin{array}{l}\text { OPG, RANKL, TRAP, CathK, PPAR- } \\
\text { gamma }\end{array}$ \\
\hline Complement & $\begin{array}{l}\text { Activation: C3, C3aR I, C5, C5aR I } \\
\text { Inhibition: CD46, CD55, CD59 }\end{array}$ \\
\hline T-Iymphocytes & CD3, CD4, CD8 \\
\hline B-lymphocytes & CDI9 \\
\hline Reference genes & GAPDH,ACT-beta, LDHA \\
\hline
\end{tabular}

Table 1. List of markers organized per biological group

\section{Results}

At 10 days (table 2), there were not many significant differences between $\mathrm{Sh}$ and $\mathrm{Ti}$, which was expected given that during the first two weeks there is an inflammatory response related to the healing process in response to the trauma caused by the osteotomy- although ARG1 (M2-macrophage marker) already presents a significant upregulation in Ti samples when compared to Sh.

\begin{tabular}{l|l|l|}
$\begin{array}{l}\text { Up-regulated } \\
\text { Significant }\end{array}$ & $\mathbf{p}$-Value & Regulation \\
\hline ARGI & $0,01 \mathrm{II}$ & $\mathrm{X} 2$ \\
\hline $\begin{array}{l}\text { Down-regulated } \\
\text { Significant }\end{array}$ & $\mathbf{p}$-Value & Regulation \\
\hline IL-I3 & 0,0339 & $\mathrm{x} 4$ \\
\hline
\end{tabular}

Table 2. 10 days, Ti compared to Sh
However, at 28 days (table 3), innate immunity markers ARG1, CD11b, NCF1 and C5aR1 are significantly up-regulated, while bone resorption markers OPG, RANKL, Cathepsin $\mathrm{K}$ and TRAP are significantly down-regulated on Ti samples when compared to Sh.

\begin{tabular}{|l|l|l|}
\hline $\begin{array}{l}\text { Up-regulated } \\
\text { Significant }\end{array}$ & $\mathbf{p}$-Value & Regulation \\
\hline CDIIb & 0,000093 & $13 \mathrm{x}$ \\
\hline ARGI & 0,0157 & $2 \mathrm{x}$ \\
\hline C5aRI & 0,0302 & $2 \mathrm{x}$ \\
\hline NCF-I & 0,0064 & $3 \mathrm{X}$ \\
\hline Down-regulated & $\mathbf{p}$-Value & Regulation \\
\hline Significant & & \\
\hline RANKL & 0,0005 & $\mathrm{X} 3$ \\
\hline OPG & 0,0065 & $\mathrm{X} 5$ \\
\hline TRAP & 0,0055 & $\mathrm{X} 4$ \\
\hline CATH K & 0,0029 & $\mathrm{X} 2$ \\
\hline
\end{tabular}

Table 3. 28 days, Ti compared to Sh

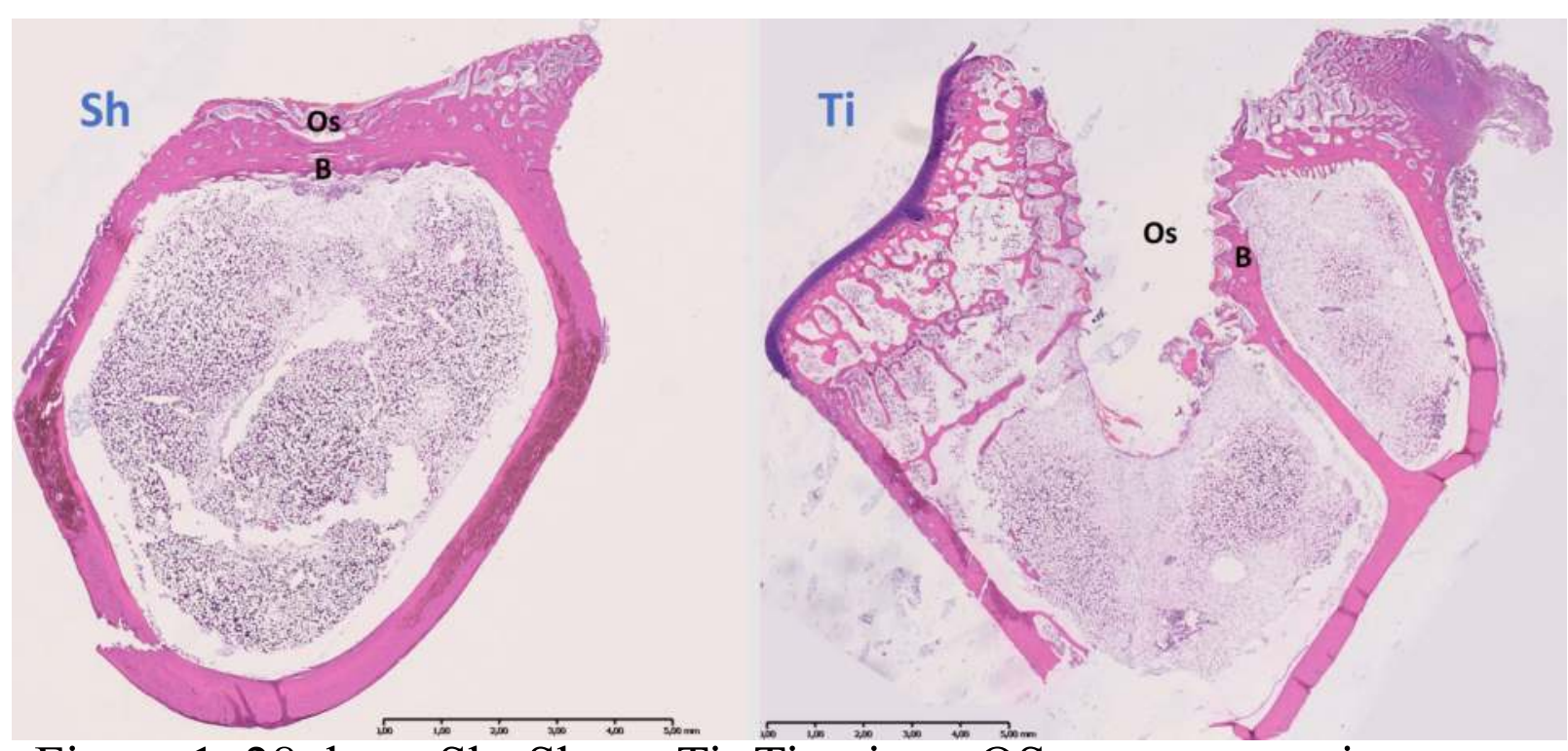

Figure 1.28 days. Sh- Sham. Ti- Titanium. OS- osteotomy site. B- new bone. Hematoxylin-Eosin staining.

\section{Conclusion}

This pilot study, within its limitations, indicates that titanium implants are not inert when in contact with bone.

The immune system seems to be activated and bone resorption mechanisms seem to be suppressed around Ti after 28 days.

More studies are needed with longer time points to understand if the immunological presence persists through time.

\section{References}

1. Albrektsson T, Dahlin C, Jemt T, Sennerby L, Turri A, Wennerberg A. Is marginal bone loss around oral implants the result of a provoked foreign body reaction? Clin Implant Dent Relat Res. 2014; 16(2):155-65.

2. Trindade R, Albrektsson T, Tengvall P, Wennerberg A. Foreign body reaction to biomaterials: on mechanisms for buildup and breakdown of osseointegration. Clin Implant Dent Relat Res. 2016 Feb; 18(1):192-203.

3. Anderson JM, Rodriguez A, Chang DT. Foreign body reaction to biomaterials. SeminImmunol 2008; 20(2):86-100.

4. Trindade R, Albrektsson T, Galli S, Prgomet Z, Tengvall P, Wennerberg A. Osseointegration and Foreign Body Reaction: Titanium implants activate the immune system and suppress bone resorption during the first 4 weeks after implantation. (submitted)

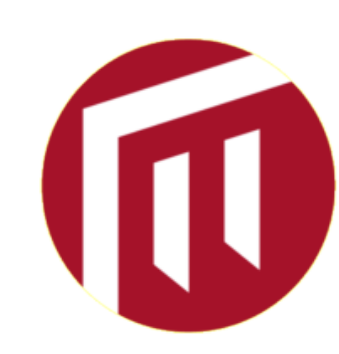

MALMÖ UNIVERSITY 